\title{
Extracellular Vesicles (EVs); Basic Science, Clinical Relevance and Applications
}

\author{
Wael Nassar ${ }^{1,3, *}$, Mervat El-Ansary ${ }^{2}$, Mostafa Abdel Aziz ${ }^{3}$ \\ ${ }^{1}$ Department of Nephrology, Sahel Teaching Hospital, General Organization of Teaching Hospitals and Institutes (GOTHI), Cairo, Egypt \\ ${ }^{2}$ Department of Clinical Pathology, Stem Cell Unit, Faculty of Medicine, Cairo University, Cairo, Egypt \\ ${ }^{3}$ Department of Nephrology, Kidney Transplantation Unit, October Six University Hospitals, Cairo, Egypt
}

\section{Email address:}

Hegaz_wn@yahoo.com (W. Nassar)

\section{To cite this article:}

Wael Nassar, Mervat El-Ansary, Mostafa Abdel Aziz. Extracellular Vesicles (EVs); Basic Science, Clinical Relevance and Applications. Cell Biology. Vol. 2, No. 6, 2014, pp. 60-71. doi: 10.11648/j.cb.20140206.12

\begin{abstract}
All types of cells of eukaryotic organisms produce and release small Nano-vesicles into their extracellular environment. Early studies have described these vesicles as "garbage bags" only to remove obsolete cellular molecules. Valadi and coworkers, in 2007, was the first who discovered the capability of circulating EVs to horizontally transfer functioning gene information between cells. These extra cellular vesicles express components responsible for angiogenesis promotion, stromal remodeling, chemo-resistance, genetic exchange and signaling pathway activation through growth factor/receptor transfer. Extracellular vesicles (EVs) represent an important mode of intercellular communication by serving as vehicles for transfer between cells of membrane and cytosolic proteins, lipids, signaling proteins and RNAs. They contribute to physiology and pathology, and they have a myriad of potential clinical applications in health and disease. Moreover, vesicles can pass the blood-brain barrier and may perhaps even be considered as naturally occurring liposomes. These cell-derived extracellular vesicles not only to represent a central mediator of the disease microenvironment, but their presence in the peripheral circulation may serve as a surrogate for disease biopsies, enabling real-time diagnosis and disease monitoring. In this review, we'll be addressing the characteristics of different types and the clinical relevance of these extracellular EVs and their potentials as diagnostic markers as well as defining therapeutic options.
\end{abstract}

Keywords: Extracellular Vesicles (EVs), Exosomes, Horizontal Gene Transfer (HGT), Microvesicles (MVs)

\section{Introduction}

Transfer of genetic information between cells had been proposed through only two mechanisms: vertical gene transfer, from parent to the next generation, and horizontal gene transfer, induced through bacteriophages [1] or viruses [2]. Recently, another mechanism of horizontal gene transfer has emerged through naturally occurring cell-derived vesicles such as exosomes and microvesicles. Extracellular vesicles are produced constitutively by most, if not all, cell types and, interestingly, contain both, mRNAs and non-coding RNAs such as small regulatory microRNAs (miRNAs) as well as proteins that can be functionally delivered between different cell types and across species [3]. As a result, such vesicles have a significant impact on physiological processes. However, this natural ability of exosomes and microvesicles to transfer genetic information might instead facilitate the spread of disease through the delivery of genetic material and/or pathogenic proteins $[4,5]$.

Extracellular Vesicles (EVs) or more accurately nanoparticles, is a term used for vesicles that are released from the plasma membrane under basal conditions or during cell stress [6].

Microvesicles are, not only produced by most cell types, but also present in most, if not all, biological fluids as well as the peripheral blood of healthy individuals in a ratio of $\sim 10(10) / \mathrm{ml}$ of blood [7, 8]. Because of the small size and heterogeneity of vesicles, their detection and classification is challenging [9].

Different types of extracellular vesicles have been identified; exosomes and microvesicles were distinguished unanimously. Apoptotic blebs or bodies had become a separate class [10-13]. Other less commonly used terms for vesicles; "ectosomes," "membrane particles," and "exosome-like vesicles" were also described. However, circulating vesicles are likely composed of both exosomes and microvesicles (MVs), and currently available purification 
methods do not allow one to fully discriminate between exosomes and MVs and that a single cell type can releases both of them in the meantime.

Confusion on the origin and nomenclature of EVs has spread through the literature as well because vesicles with the size of exosomes that bud at the plasma membrane have also been called exosomes [16, 17]. It should be noted that most studies have not clearly defined the origin of EVs under study; therefore, we will mostly refer to EVs rather than MVs or exosomes. A major ongoing challenge is to establish methods that will allow one to discriminate between exosomes and MVs. Differences in properties such as size, morphology, buoyant density, and protein composition seem insufficient for a clear distinction [18].

\section{Historical Background}

Thirty years ago, two papers had been published within a week of each other-reported that, in reticulocytes, transferrin receptors associated with small vesicles are literally jettisoned from maturing blood reticulocytes into the extracellular space $[14,15]$. The name "exosome" for these extracellular vesicles was coined a few years later by Rose Johnstone, although the term was initially introduced for vesicles ranging from 40 to $1,000 \mathrm{~nm}$ that are released by a variety of cultured cells [19], later, this nomenclature was adopted for 40-100-nm vesicles released during reticulocyte differentiation as a consequence of multivesicular endosome (MVE) fusion with the plasma membrane [20,21]. One decade later, exosomes were found to be released by $\mathrm{B}$ lymphocytes and dendritic cells through a similar route $[22,23]$.

\section{The Main Characteristics of Extracellular Vesicles (EVs)}

\subsection{Types of EVs}

Two common types were distinguished unanimously [i.e., exosomes and microvesicles (also called shedding vesicles, shedding microvesicles, or nanoparticles)]. A third type; apoptotic vesicles (also called apoptotic blebs, or apoptotic bodies) has become a separate class $[10,12]$. In addition, "ectosomes," "membrane particles," and "exosome-like vesicles" were distinguished on the basis of the physical and chemical characteristics of vesicles, including size, density, appearance in microscopy, sedimentation, lipid composition, main protein markers, and subcellular origin [i.e., originating from intracellular compartments (exosomes) or plasma membranes] [10].

\subsection{Isolation and Characterization of EVs}

One major challenge in the field is to improve and standardize methods for EV isolation and analysis [25]. Because of their small size, vesicles are below the range of conventional detection methods. Isolation of EVs is mostly from the supernatants of cultured cells grown by performing differential ultracentrifugation (100000-200000 g). The differences in floatation velocity can be used to separate differently sized classes of EVs [24]. Most size determinations of vesicles are based on the transmission electron microscopy (TEM).

Besides differential centrifugation, filtration can be applied to isolate vesicles. Although the pore size of filters is often well defined, increasing forces have to be applied with decreasing pore size, which may result in artifacts [26].

Flow field-flow fractionation (FFFF) [27], a technique that fractionates particles based on differences in their diffusion properties without applying forces equally high to differential centrifugation. Although FFFF is successfully applied to isolate exosomes from human neural stem cells [28], FFFF is not widely applied because it requires extensive optimization of the settings and is relatively expensive.

Characterization of isolated EVs requires complementary biochemical (immune-blotting), mass spectrometry, and imaging techniques. Quickly frozen, vitrified vesicles analyzed by cryo-electron microscopy indeed show that exosomes and other EVs have a perfectly rounded shape [29]. Complementary to electron microscopy, nanoparticle tracking analysis allows determination of the size distribution of isolated EVs based on the Brownian motion of vesicles in suspension [30]. Because conventional flow cannot distinguish between vesicles that are smaller than $300 \mathrm{~nm}$, a novel high resolution flow cytometry-based method has been recently developed for quantitative high throughput analysis of individual (immune-labeled) Nano-sized vesicles [31, 32].

\subsection{The Molecular Composition of EVs}

Most, if not all, cells types can secrete vesicles both in basal conditions and upon exposure to stress. Microvesicles are nanoparticles that are generated by direct budding of the plasma cell membrane, with a size ranging from 50 to 1000 $\mathrm{nm}$, express surface markers such as integrin- $\beta$, CD40 ligand and selectins as well as surface protein receptors that characterize the membrane composition of their cells of origin [33-35]. On the other hand, exosomes are derived from endocytic pathway of different cell types, express contain endosome-associated proteins such as Annexins, Flotillin, Alix, Tsg101 and Tetraspanins, such as CD63, CD81, CD82, CD53, CD9 and CD37 [36-38]. Exosomes from a variety of cells are highly enriched in cholesterol, sphingomyelin, and hexosylceramides, in addition to phosphatidyl-choline and phosphatidyl-ethanolamine. The fatty acids in exosomes are saturated or monounsaturated [39].

Interestingly, extracellular vesicles were demonstrated to contain both mRNA and miRNA. mRNA can be functionally transported and translated into proteins whereas, miRNA can induce translation repression or less often degradation of mRNA of the target cells [40-44]. It is of importance to notice that, in mammals, each mRNA molecule is translated into as many as 2800 protein molecules [149]. Recently, analysis of RNA from EVs demonstrated that, in addition to mRNA and miRNA, EVs also contain small interfering RNAs (siRNAs) and piwi RNA (piRNAs). The piwiRNA is specifically 
characterizes the germ cell line [45, 46]. Many RNAs that were isolated with EVs vary from the RNA profiles of the originating cells $[31,40,41]$, suggesting the existence of active sorting mechanisms of RNA molecules and that they are selectively incorporated into EVs [26]. It is well documented that a single miRNA can influence hundreds of mRNA gene transcripts and thereby, it is proposed to be implicated as a key player in virtually every cell process [47]. While the majority of miRNAs are found intracellularly, a virtual number have been detected outside cells. One important mechanism explaining the stability of extracellular RNAs, despite high extracellular RNase activity, is thought to be packing within extracellular vesicles (EVs) which are impermeable to RNases [48]. To date, more than 2000 extracellular miRNA has been discovered in humans, some of them are contained in EVs (10\%) and most (90\%) are associated with lower-molecular-mass complexes bound to Argonaut 2 (Ago2), nucleophosmin-1 (NPM1) and high density lipoproteins (HDL) [150].

\subsection{Biogenesis and Release of EVs}

Ribosomes are the factory through which mRNA is translated into non-functioning polypeptides (random coil). Amino acids of the random coil interact with each other to produce a functional three-dimensional protein structure in the endoplasmic reticulum [50]. Only properly folded proteins are then transported through the rough ER-Golgi pathway. In case the process of three dimensional structures produced mal-folded protein, several endoplasmic reticulum chaperone proteins are released to correct misfolded or unfolded proteins; in this reaction glucose, calcium and redox buffers are required for successful protein folding [51]. One major function of chaperones is to prevent newly synthesized polypeptides from aggregation and pass into nonfunctional structures. It is important here to remember that chaperones are not present when the macromolecules have correctly completed the processes of folding [52, 53], which might be, in the future, implicated to discriminate exosomes originating from stressed cells from those from non-stressed cells. Mal-folded proteins are then, sent back to the cytosol in transient complexes that prevents these proteins from secretion through the endosomal pathway [54, 55].

The mechanism of formation of exosomes is the process of the endosomal pathway, including endocytic vesicles, early endosomes, late endosomes; also known as multivesicular bodies (MVBs) and lysosomes [56, 57]. The pathway of multivesicular endosomes (MVEs) that are prone to fuse with lysosomes and predestined for lysosomal degradation, differ from the pathway of secretory MVEs predestined to become secreted as exosomes; it can be either: ESCRT-dependent or ESCRT-non-dependent pathways in which exosomal release process might be controlled by natural ceramide biosynthesis enzyme (nSMase2). However, the release is overall modulated by extracellular signals $[58,59]$.

Endosomal sorting complex responsible for transport (ESCRT) is a four multi-protein complexes assembled within the MVEs: The ESCRT- 0, I and II complexes recognize membrane proteins at the endosomal membrane, whereas the ESCRT-III complex may be responsible for actual scission of intraluminal vesicles) ILVs [60-63].

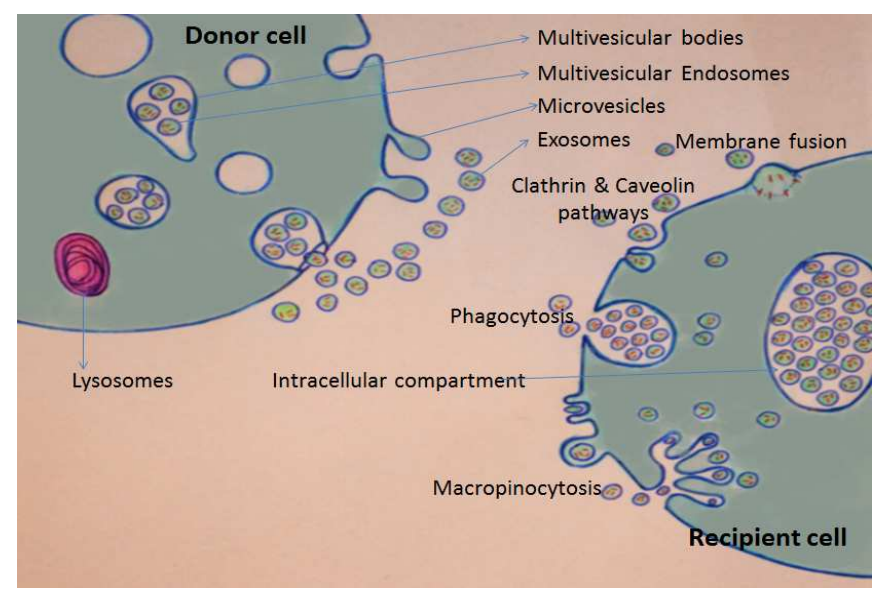

Figure 1. At the "DONOR CELL": Release of MVs and exosomes. MVs bud directly from the plasma membrane, whereas exosomes are represented by small vesicles of different sizes that are formed as the ILV by budding into early endosomes and MVEs and are released by fusion of MVEs with the plasma membrane. At the "RECEPIENT CELL": Pathways shown to participate in EV uptake by target cells, including clathrin mediated endocytosis (CME), caveolin-dependent endocytosis (CDE), phagocytosis, macropinocytosis and plasma or endosomal membrane fusion.

The external membrane of the MVBs fuses with the plasma membrane of the cell, resulting in release of their segregated vesicles through the process of exocytosis to the extracellular space. In all human cells, exocytosis can be either constitutive (non- calcium-dependent) or regulated (calcium-dependent), so as extracellular vesicles exocytosis is expected [64].

Disturbances in redox regulation, calcium regulation, glucose deprivation, and viral infection $[65,66]$ or the over-expression of proteins [67], properly folded or mal-folded, can lead to endoplasmic reticulum (ER) stress. This is a state in which the folding of proteins slows, leading to further accumulation of miRNA species and increase in unfolded proteins. Unfolded protein crowd will be developed, resulting in more slowing of the cell machinery, and finally the unfolded protein response (UPR) develop, with the activation of the signaling pathways that lead to increasing the production of molecular chaperones involved to correct protein folding. This chaperones aim at restoring normal function of the cell by halting protein translation and degrading mis-folded proteins. If these objectives are not achieved within a certain lapse of time or the disruption is massive, the UPR aims towards activation of apoptosis (e.g. p53 pathway activation) $[68,69]$.

The $\mathrm{p} 53$ protein activation respond to a wide variety of stress signals including geno-toxic stress, hypoxia, and even the expression of activated oncogenes [70], which, for instance, could be part of the mis-folded proteins. However, it has been shown that overexpression of TSAP6, a p53-regulated gene and is transcribed in response to stress [54, 55, 71-73]. Thus, the requirement for $\mathrm{p} 53$ in exosome production might be through the ability of p53 to up-regulate 
TSAP6 transcription. Expression of the TSAP6 gene allows the cells with or without functional p53 to produce exosomes $[54,74]$. This finding supports the notion that, cell stress, with or without activation of the apoptotic pathway, can increase the production of exosomes.

\subsection{Mechanisms of Action of EVs at the target Cells}

The exact mechanisms by which EVs interact with recipient cell membrane and/or delivering their contents of proteins, lipids, and RNAs; is still not fully understood [31]. Target cell specificity for binding of exosomes (or other EVs) is likely to be determined by adhesion molecules and also tetraspanin complexes together with extracellular signals which appear to influence target cell selection in vitro and in vivo [75].

Various mechanisms for EV uptake have been proposed, including clathrin mediated endocytosis (CME), caveolin dependent endocytosis (CDE), phagocytosis, macro pinocytosis and plasma or endosomal membrane fusion [76] (Fig. 1). Regardless the mechanisms; interaction between EVs and recipient cell membrane may include: (i) ligand/receptor binding, (ii) fusion, (iii) internalization of their content or, combination of these [26]. Extracellular vesicles may directly activate the recipient cell by acting as signaling complexes [77, 78]. It worthwhile to mention that during cell exocytosis, proteins embedded in the vesicle membrane fuse and become part of the plasma membrane and the side of the protein that was facing the inside of the vesicle now faces the outside of the cell. This mechanism is important for the regulation of trans-membrane receptors and transporters [79]. Whether or not this is the case for fusion of exosomal membrane with the target cell membrane, need to be investigated. However, this can reconcile the discrepancy of whether phosphatidyl serine (PS) exposed by EVs [80] or increased due to exposure to shearing forces associated with ultracentrifugation [81].

After being endocytosed, EVs may be distend to the endosomal pathway targeted to lysosomes for degradation or release their functionally active nucleoproteins load inside the recipient cell [40]. mRNA can be translated in the recipient cells via ribosomes, whereas miRNAs and siRNA are known to regulate more than $80 \%$ of all protein-encoding genes through gene silencing effect [82-84].

It is therefore conceivable that EV may play a critical role in signaling mechanisms essential for normal biological functions, as well as disseminating pathogenesis through interaction with recipient cells.

\section{Functions of EVs}

It has become evident that EVs are important factors involved in a wide range of physiological and pathological processes. As the apical/baso-lateral membrane distribution is lacking in all blood cells including immune cells, transient exposure time and interaction between EVs and circulating blood cells would have been expected, at least theoretically, to be some folds higher than that of organ fixed endothelial cells. This may explain the wide range of involvement of immune cells in a diversity of cytopathic effects of exosomes. For this reasons it would be expected that blood cells, including immune cells, are, at least chronologically, the first to interact with the circulating EVs. Extracellular vesicles have since been demonstrated to be released by a variety of cells of the immune system, including dendritic cells, macrophages, B cells, T cells, and NK cells [80]. These extracellular vesicles have been demonstrated to be key mediators/regulators of normal immune responses [85]. So, Dauglas Taylor was right to say "one can view tumors as a "cyber-terrorist" using these extracellular vesicles to elicit aberrant immune regulation" [26].

\subsection{Extracellular Vesicles Effects on the Immune Systems}

\subsubsection{EVs as Immune-Suppressants}

By transporting ligands and receptors, exosomes can orchestrate cell growth and development, and modulate the immune system. Activated $\mathrm{T}$ cells and peripheral blood mononuclear cells release vesicles exposing Fas ligand (FasL), a death receptor ligand, which may have immune regulatory function [86]. During first-trimester, trophoblast cells from a pregnant uterus release exosomes exposing FasL, which are capable of inducing Fas-mediated T-cell death, suggesting that exosomes contribute to this immune privilege [87, 88]. Moreover, epithelial cells from ovarian cancer release FasL-exposing microvesicles that are capable of inducing T-cell apoptosis [89]. Exosomes isolated from pleural effusion of patients with mesothelioma down-regulate NKG2D expression of NK cells and CD8+ cells via a transforming growth factor (TGF)- $\beta$-dependent mechanism, indicating that NKG2D may be one of the targets for exosome mediated immune evasion [90, 91]. Moreover, exosomes have the ability to prevent allergic sensitization in allergic asthmatic patients [93]. Immature or suppressive DCs reduce adaptive immune activation by inducing $\mathrm{T}$ cell apoptosis and thus promoting a tolerogenic immune response as seen in murine models of transplantation and autoimmune diseases. Suppressive exosomes may also influence the balance between pro-inflammatory and anti-inflammatory effector $\mathrm{T}$ cells inducing $\mathrm{T}$ helper Th17/Th1 cells to differentiate into Th2 and Foxp3+ regulatory $\mathrm{T}$ cells [92]. For this reason, exosomes could potentially be used to avoid graft rejection or as a treatment of autoimmune diseases. Moreover, the latent membrane protein-1 (LMP-1) of Epstein-Barr virus (EBV), which is exposed on exosomes from EBV-infected cells, inhibits the proliferation of peripheral blood mononuclear cells. This mechanism is thought to be relevant in development of EBV-associated tumors, such as nasopharyngeal carcinoma and Hodgkin's disease, by allowing tumor cells to evade the immune system [93]. Taken together, exosomes are likely to orchestrate the efficacy of the immune system by a whole set of different mechanisms important not only for normal development but also for tumor development.

\subsubsection{EVs as Immune-Stimulants}

EVs are used by cells not only to suppress the immune system but also to present antigens and stimulating the 
immune reaction. Human intestinal epithelial cells release exosomes exposing MHC class I and MHC class II molecules at both the apical and basolateral sides, suggesting a possible involvement of exosomes in the transcellular transport of antigens from the lumen of the gut to immune cells [94, 95]. The initiation of T-cell-mediated antitumor immune responses requires uptake, processing, and presentation of tumor antigens by DCs. Exosomes from mouse tumor cells transfer tumor antigens to DCs in vivo [96]. Exosomes exposing MHC class II-antigen complexes are secreted from antigen-loaded DCs when these cells contact antigen-specific CD4 T cells. This secretion is preceded by accumulation of intraluminal vesicles exposing both MHC class II and CD9 in MVEs [97]. Mature dendritic cells also secrete exosomes showing functional peptide-bearing MHC class I and II molecules on their membranes that can directly bind to T-cell receptors and activate CD4+ or CD8+ T cells inducing an adaptive immune response [98, 99].

\subsection{Other Clinically Relevant Functions of EVs}

\subsubsection{Role of EVs in Inflammation}

Cell-derived vesicles from stressed cells can trigger the production of pro-inflammatory cytokines by activating targeted cells independent of the presence or absence of previous infections. This activation results in expression and production of tissue factors and interleukins [100]. The elegant experiment of Deng and his colleagues shows that EVs derived from adipose tissue when intravenously injected into wild type C57BL/6 mice resulted in development of insulin resistance, whereas injection into TLR-4 knockout B6 mice the insulin resistance was not marked due to the effect of increased levels of TNF- $\alpha$ and IL-6 [101]. Based on this experiment, the gradual progressive dissemination of insulin resistance throughout the body may be attributed, at least in part, to EVs released from inflamed adipose tissues which may open the gate for a new modality of treatment for insulin resistance type 2 diabetic patients [102]. Another example is that extracellular vesicles from human atherosclerotic plaques have been shown to mediate the functional transfer of ICAM-1 to endothelial cells of neighboring healthy cells, thereby promoting the adhesion of monocytes and trans-endothelial migration [103]. Thus, plaque EVs may further facilitate atherosclerotic plaque progression. Moreover, the ability of EVs to modulate the inflammatory response is not limited to blood. Autologous EVs from synovial fluid and EVs from $\mathrm{T}$ cells, monocytes, and platelets trigger the production and release of interleukins 6 and 8 , matrix metallo-proteases, monocyte- chemotactic proteins 1 and 2, vascular endothelial growth factor (VEGF), and ICAM-1 by synovial fibroblasts, indicating that these vesicles may enhance the destructive activity of these fibroblasts in rheumatoid arthritis [104].

\subsubsection{Extracellular Vesicles and Viruses}

Viruses use vesicles for infection and survival. HCV entry receptors may partly contribute to exosome uptake even in the absence of viral envelope or core proteins [105]. HCV entry receptors CD81 and SR-BI are also known to localize in lipid rafts of exosomes [106], supporting a hypothetical role of these receptors in exosome uptake by the neighboring healthy hepatocytes. The cytopathic effect of HCV infection differs between complete virus genome and exosome mediated hepatocyte infection (reinfection). While complete free virus genome mostly produces cell lysis and apoptosis, exosomes mediated infection or reinfection, can produce an antibody-resistant cell-to-cell transmission route and establish a productive infection even in the absence of viral envelope or core proteins [107-109]. Moreover, in membranoproliferative (mesangiocapillary) glomerulonephritis (MPGN) associates $\mathrm{HCV}$, mesangial expansion is largely attributed to macromolecular deposits (EVs) and to lesser extent the direct pathogenetic effect of the virus [110], supporting the hypothetical role of exosome in transmitting $\mathrm{HCV}$ genetic information to the kidney [111]. Recently, it has been shown that exosomes released from $\mathrm{HIV}$-infected cells contain negative regulatory factor, which induces apoptosis of uninfected cells though these cells do not contain the RNA of the virus itself (bystander effect) [112], besides, EVs produced in response to HIV virus are more infectious to CD4 T cells than cell-free viral particles [113]. Moreover, human herpes virus 4 or EBV encodes RNAs that can be transferred from infected to uninfected cells by EVs [114-116]. The uptake of EVs from EBV-infected cells by epithelial cells results in activation of growth-stimulating signaling pathways and can manipulate the growth characteristics of neighboring cells $[117,118]$.

\subsubsection{Tumor Growth, Metastasis, and Angiogenesis and EVS}

One of the molecular mechanisms underlying the intercellular transfer of metastatic activity is the transfer of an oncogenic growth factor receptor or their ligand. The ability of exosomes to promote metastasis and angiogenesis can be increased when exosomes are released under hypoxic conditions (i.e., conditions that many tumors encounter when growing) [119]. Cancer cells can release vesicles containing the Fas-associated death domain, a key adaptor protein that transmits apoptotic signals and becomes lost in many cancer cells [120]. In addition, exosomes may protect tumor cells from entering or accumulation of antitumor drugs, thereby possibly contributing to (multi) drug resistance. For instance, exosomes from HER2-overexpressing breast cancer cell lines, or exosomes present in serum from patients with breast cancer, capture the humanized antibody trastuzumab, thereby reducing the effective concentration of this anticancer drug [121]. Vesicles may also contribute to drug resistance by exchanging drug transporters between cells. There are other ways in which vesicles promote tumor growth, including the release of active matrix-degrading enzymes, stimulation of angiogenesis [123], and production of TF [124]. Vesicles can expose phosphatidylserine (PS), a negatively charged phospholipid to which (activated) coagulation factors can bind and assemble in the presence of calcium ions, thereby promoting coagulation $[125,126]$. Cell-derived vesicles from tumors are strongly pro-coagulant [127]. This activity was due 
to the exposure of TF, the initiator of coagulation [128].

\subsubsection{Neurodegenerative Disorders}

Parkinson's disease is characterized by intracellular aggregates of $\alpha$-synuclein, the Lewy bodies, in dopaminergic neurons. Alvarez-Ervit and colleagues showed that alpha-synuclein released from cells over expressing this protein is efficiently transferred to recipient normal cells through exosomes [129]. Moreover, Surgucheva showed that another member of the synuclein family, $\gamma$-synuclein, secreted from neuronal cells into exosomes can be transmitted to glial cells, thus promoting the aggregation of intracellular proteins [130]. Alzheimer's disease (AD); characterized by extracellular aggregates of beta amyloid peptides known as amyloid plaques [131], exosome-associated-amyloid peptides that may be involved in plaque formation playing a significant role in the pathogenesis and the progression of $\mathrm{AD}$, besides, tau proteins are mainly secreted through exosomes in vitro and in vivo [133].

\subsubsection{Cardiovascular Disorders and EVs}

Exosome-mediated cellular communication is also involved in the pathogenesis of cardio-vascular disease. Serum levels of miR-1 and mir-133a are localized inside exosomes and are significantly increased in patients with acute myocardial infarction and angina pectoris [134]. Furthermore, circulating platelet-derived exosomes from septic patients induced myocardial dysfunction in isolated heart and papillary muscle preparations in a nitric-oxide dependent mechanism [134]. Extracellular vesicles from human atherosclerotic plaques have been shown to mediate the functional transfer of ICAM-1 to endothelial cells of neighboring healthy cells, thereby promoting the adhesion of monocytes and trans-endothelial migration [103]. Thus, plaque EVs may further facilitate atherosclerotic plaque progression. Exosomes enriched in miR-143/145; regulated by KLF2 (Krïppel-like factor 2), a key transcription factor able to mediate an athero-protective endothelial phenotype generated by shear stress. They showed that these miRNAs are transferred into smooth muscle cells (SMCs) acting on miRNA targets thus preventing SMC de-differentiation [135].

\subsubsection{Autoimmune Disorders and EVs}

Synovial fluid obtained from patients with RA contain APO2L/TRAIL that has been associated with exosomes in synovial fibroblasts appears to be low compared to that found in the synovial fibroblast of control patients [137]. Martinez-Lostao and co-workers have recently demonstrated that tethering APO2L/TRAIL to the liposome membrane may substantially reduce synovial hyperplasia and inflammation in rabbit knee joints [136]. It has been recently reported that inappropriate clearance of apoptotic vesicles is considered to be the primary cause of developing systemic autoimmune diseases [138].

\section{Diagnostic Potentials of EVs}

Recently, evidences are accumulating supporting the promising potential of EVs as disease biomarkers. Exosomes are stable, disease-specific, disease characterizing, and can also predict prognosis [139]. Temporal changes in exosomal nucleoprotein contents have been demonstrated to accurately predict disease recurrence and overall patient survival [140]. Moreover, the proteomic and genomic profiles of circulating exosomes provide a real-time monitor of therapeutic response. By correlating these circulating markers with real-time clinical parameters, circulating exosomes profile can be considered a "liquid biopsy" of cells [141].

Prostate-surface antigen (PSAs) had been the first urinary EVs biomarker recognized. It is associated with exosomes in urine of patients with prostate cancer [142]. Furthermore, exosomes in cerebrospinal fluid of patients with Alzheimer's disease contain phosphorylated Thr181, which is an established biomarker of this disease [143]. Significant increase in the levels of microRNAs has also been observed in extracellular vesicles from patients with ovarian cancer, compared to the non-malignant samples is another evidence of the potential diagnostic role of EVs [141].

Most of studies are focusing on selection of one or a few EVs miRNAs as disease biomarkers, whereas, every single miRNA has numerous potential targets and also many miRNAs can target the same protein. Moreover, miRNAs usually target proteins from one or more related pathways. All these factors need to be considered to unveil the role of miRNA as diagnostic biomarkers to facilitate and fasten shifting of EVs from bench to bed side.

\section{Therapeutic Potentials of EVs}

Exosomes have a specific cell tropism, according to their characteristics, which can be used to target them to specific tissues and/or organs through a mechanism similar to a cellular signaling based response [144]. Moreover, exosomes nanoparticles can be engineered and/or loaded with several molecules (drugs, small molecules and nanoparticles) and targeted to specific organs, and therefore can be used for the delivery of therapeutic agents [145]. Transfection of an expression vector and loading of modified vesicles with BACE1 siRNA has been efficiently investigated, to retard the production of unfolded amyloid proteins, in animal and preclinical trials to deliver siRNA into the mouse brain of Alzheimer's disease with promising results [146]. Ohno et al. showed that systemically injected exosomes targeted to EGFR-expressing breast cancer cells may deliver Let-7a antitumor miRNA (antagomirs), and thus represent a vehicle for conveying drugs to tumors [147]. It has recently been demonstrated that extracellular vesicles or microvesicles (MVs) released from different mesenchymal stem cells are an integral component of cell-to-cell communication network involved in tissue regeneration [148, 149], and therefore may contribute to the paracrine action of MSCs. Because of their potential therapeutic application in acute tissue injury of different organs (heart, kidney, lung and liver), cell-free MSCs extracellular vesicles are currently used in clinical trials of a wide range of diseases [150]. 


\section{Conclusion}

During the past decade, the interest of physicians and molecular biologist in EVs has expanded logarithmically. EVs are abundantly released by most cells and present in body fluids, carry RNAs, and show regulatory functions that represent a perfect tool for early diagnosis and therapeutic vehicle for a wide range of diseases. Although the clinical application of EVs remains years away, the significance of their diagnostic and therapeutic potential is not an issue for debate. Deciphering the molecular mechanisms of EVs biogenesis and function as well as more accurate and standardized purification methods is required for the implementation of EVs in clinical practice. To help coordinate these enormous challenges, the International Society for Extracellular Vesicles (ISEV) was launched in 2011.

\section{Acknowledgements}

The authors gratefully acknowledge Rashad S. Barsoum, Professor of Internal Medicine and Nephrology, Faculty of Medicine, Cairo University, Egypt, for his unlimited help and support. We wish also to acknowledge Dr. Mayar $W$ N., Faculty of Medicine, October Six University, whose effort was behind most of the steps of this work.

\section{Conflict}

We, the authors of this review, declare that there is no conflict of interest that could be perceived as prejudicing the impartiality of the research. We fully declare that no financial or other potential conflict of interest.

\section{References}

[1] Ochman, H., Lawrence, J.G. and Groisman, E.A. (2000) Lateral gene transfer and the nature of bacterial innovation. Nature, 405, 299-304.

[2] Walther, W. and Stein, U. (2000) Viral vectors for gene transfer: a review of their use in the treatment of human diseases. Drugs, 60, 249-271.

[3] Valadi, H. (2007) Exosome-mediated transfer of mRNAs and microRNAs is a novel mechanism of genetic exchange between cells. Nat. Cell Biol., 9, 654-659.

[4] Bellingham, S.A. and Hill, A.F. (2012) Exosomes: vehicles for the transfer of toxic proteins associated with neurodegenerative diseases? Front. Physio., 3, 124.

[5] Conde-Vancells J, Rodriguez-Suarez E, Embade N, Gil D, Matthiesen R, Valle M, Elortza F, Lu SC, Mato JM, and Falcon-Perez JM (2008) Characterization and comprehensive proteome profiling of exosomes secreted by hepatocytes. $J$ Proteome Res 7:5157-5166.

[6] Morel O, Jesel L, Freyssinet JM, and Toti F (2011) Cellular mechanisms underlying the formation of circulating microparticles. Arterioscler Thromb Vasc Biol 31:15-26.

[7] Yuana Y, Oosterkamp TH, Bahatyrova S, Ashcroft B, Garcia
Rodriguez P, Bertina RM, and Osanto S (2010). Atomic force microscopy: a novel approach to the detection of nanosized blood microparticles. J Thromb Haemost 8:315-323.

[8] Dragovic RA, Gardiner C, Brooks AS, Tannetta DS, Ferguson DJ, Hole P, Carr B, Redman CW, Harris AL, Dobson PJ, et al. (2011). Sizing and phenotyping of cellular vesicles using Nanoparticle Tracking Analysis. Nanomedicine 7:780-788.

[9] Edwin van der Pol, Anita N. Bo“ing, Paul Harrison, Augueste Sturk, and Rienk (2012). Classification, Functions, and Clinical Relevance of Extracellular Vesicles. Nieuwland, Pharmacol Rev 64:676-705.

[10] The'ry C, Ostrowski M, and Segura E (2009). Membrane vesicles as conveyors of immune responses. Nat Rev Immunol 9:581-593.

[11] Beyer C and Pisetsky DS (2010). The role of microparticles in the pathogenesis of rheumatic diseases. Nat Rev Rheumatol 6:21-29.

[12] Mathivanan S, Ji H, and Simpson RJ (2010). Exosomes: extracellular organelles important in intercellular communication. J Proteomics 73:1907-1920.

[13] Yi Lee, Samir EL Andaloussi and Matthew J.A. Wood (2012). Exosomes and microvesicles: extracellular vesicles for genetic information transfer and gene therapy. Human Molecular Genetics, R1-R10.

[14] Harding,C., Heuser,J. ,and Stahl, P.(1983).Receptor-mediated endocytosis of transferrin and recycling of the transferrin receptor in ratreticulocytes. J. CellBiol. 97, 329-339.

[15] Pan,B.T., Blostein,R.,and Johnstone, R. M.(1983). Loss of the transferrin receptor during the maturation of sheep reticulocytes in vitro: an immunological approach. Biochem. J. $210,37-47$

[16] Lee Y, El Andaloussi S, Wood MJ (2012): Exosomes and microvesicles: extracellular vesicles for genetic information transfer and gene therapy. Hum Mol Genet. 21(R1):R125-134.

[17] Booth AM, Fang Y, Fallon JK, Yang JM, Hildreth JE, and Gould SJ (2006) Exosomes and HIV Gag bud from endosome-like domains of the T cell plasma membrane. J Cell Biol 172:923-935.

[18] Bobrie A, Colombo M, Raposo G, and The'ry C (2011) Exosome secretion: molecular mechanisms and roles in immune responses. Traffic 12:1659-1668.

[19] Trams, E.G., C.J. Lauter, N. Salem Jr., and U. Heine (1981). Exfoliation of membrane ectoenzymes in the form of micro-vesicles. Biochim. Biophys. Acta. 645:63-70.

[20] Harding, C., J. Heuser, and P. Stahl. (1984). Endocytosis and intracellular processing of transferrin and colloidal gold-transferrin in rat reticulocytes: demonstration of a pathway for receptor shedding. Eur. J. Cell Biol. 35:256 263.

[21] Pan, B.T., K. Teng, C. Wu, M. Adam, and R.M. Johnstone (1985). Electron microscopic evidence for externalization of the transferrin receptor in vesicular form in sheep reticulocytes. J. Cell Biol. 101:942-948.

[22] Raposo, G., H.W. Nijman, W. Stoorvogel, R. Liejendekker, C.V. Harding, C.J. Melief, and H.J. Geuze (1996). B lymphocytes secrete antigenpresenting vesicles. J. Exp. Med. 183:1161-1172. 
[23] Zitvogel, L., A. Regnault, A. Lozier, J. Wolfers, C. Flament, D. Tenza, P. Ricciardi-Castagnoli, G. Raposo, and S. Amigorena. 1998. Eradication of established murine tumors using a novel cell-free vaccine: dendritic cell-derived exosomes. Nat. Med. 4:594-600.

[24] Aalberts, M., F.M. van Dissel-Emiliani, N.P. van Adrichem, M. van Wijnen, M.H. Wauben, T.A. Stout, and W. Stoorvogel. 2012. Identification of distinct populations of prostasomes that differentially express prostate stem cell antigen, annexin A1, and GLIPR2 in humans. Biol. Reprod. 86:82.

[25] Théry, C., S. Amigorena, G. Raposo, and A. Clayton. 2006. Isolation and characterization of exosomes from cell culture supernatants and biological fluids. Curr. Protoc. Cell Biol. Chapter 3:Unit 3.22.

[26] Douglas D. Taylor and Cicek Gercel-Taylor (2013).The origin, function, and diagnostic potential of RNA within extracellular vesicles present in human biological fluids. Frontiers in Genetics.Vol. 4, Article 142.

[27] Soo, C.Y., Y. Song, Y. Zheng, E.C. Campbell, A.C. Riches, F. Gunn-Moore, and S.J. Powis (2012). Nanoparticle tracking analysis monitors microvesicle and exosome secretion from immune cells. Immunology. 136:192-197.

[28] Nolte-’t Hoen, E.N., E.J. van der Vlist, M. Aalberts, H.C. Mertens, B.J. Bosch, W. Bartelink, E. Mastrobattista, E.V. van Gaal, W. Stoorvogel, G.J. Arkesteijn, and M.H. Wauben (2012b). Quantitative and qualitative flow cytometric analysis of nanosized cell-derived membrane vesicles. Nanomedicine. 8:712-720.

[29] Van der Vlist, E.J., E.N. Nolte-'t Hoen, W. Stoorvogel, G.J. Arkesteijn, and M.H. Wauben (2012). Fluorescent labeling of nano-sized vesicles released by cells and subsequent quantitative and qualitative analysis by high-resolution flow cytometry. Nat. Protoc. 7:1311-1326.

[30] Subra, C., K. Laulagnier, B. Perret, and M. Record (2007). Exosome lipidomics unravels lipid sorting at the level of multivesicular bodies. Biochimie. 89:205-212.

[31] Raposo G, Stoorvogel W. Extracellular vesicles: exosomes, microvesicles, and friends (2013). J Cell Biol. 200: 373-83.

[32] Ratajczak, J., M. Wysoczynski, F. Hayek, A. Janowska-Wieczorek, and M.Z. Ratajczak (2006). Membrane-derived microvesicles: important and underappreciated mediators of cell-to-cell communication. Leukemia. 20: 1487-1495.

[33] Valadi, H., K. Ekström, A. Bossios, M. Sjöstrand, J.J. Lee, and J.O. Lötvall (2007). Exosome-mediated transfer of mRNAs and microRNAs is a novel mechanism of genetic exchange between cells. Nat. Cell Biol. 9:654-659.

[34] Mittelbrunn, M., C. Gutiérrez-Vázquez, C. Villarroya-Beltri, S. González, F. Sánchez-Cabo, M.A. González, A. Bernad, and F. Sánchez-Madrid (2011). Unidirectional transfer of microRNA-loaded exosomes from $\mathrm{T}$ cells to antigen-presenting cells. Nat. Commun. 2:282.

[35] Montecalvo, A., A.T. Larregina, W.J. Shufesky, D.B. Stolz, M.L. Sullivan, J.M. Karlsson, C.J. Baty, G.A. Gibson, G. Erdos, Z. Wang, et al (2012). Mechanism of transfer of functional microRNAs between mouse dendritic cells via exosomes. Blood. 119:756-766.

[36] Nolte-'t Hoen, E.N., H.P. Buermans, M. Waasdorp, W.
Stoorvogel, M.H. Wauben, and P.A. 't Hoen (2012a). Deep sequencing of RNA from immune cell-derived vesicles uncovers the selective incorporation of small non-coding RNA biotypes with potential regulatory functions. Nucleic Acids Res. 40:9272-9285.

[37] Giovanni Camussi and Peter J. Quesenberry (2013). Perspectives on the Potential Therapeutic Uses of Vesicles. Exosomes microvesicles, Vol. 1, 6:2013.

[38] Kalra, H., R.J. Simpson, H. Ji, E. Aikawa, P. Altevogt, P. Askenase, V.C. Bond, F.E. Borràs, X. Breakefield, V. Budnik, et al (2012). Vesiclepedia: a compendium for extracellular vesicles with continuous community annotation.PLoS Biol. 10:e1001450.

[39] Alberts, Bruce; Alexander Johnson, Julian Lewis, Martin Raff, Keith Roberts, and Peter Walters (2002). "The Shape and Structure of Proteins". Molecular Biology of the Cell; Fourth Edition. New York and London: Garland Science.

[40] Bernales, Papa and Walter (2006). Intracellular signaling by the unfolded protein response. Annual Review of Cell and Developmental Biology, 22: 487-508

[41] Richardson RT, Alekseev OM, Grossman G et al. (July 2006). "Nuclear Autoantigenic Sperm Protein (NASP), a Linker Histone Chaperone That is Required for Cell Proliferation". Journal of Biological Chemistry 281 (30): 21526-34. doi:10.1074/jbc.M603816200. PMID 16728391.

[42] Ellis RJ (July 2006). "Molecular chaperones: assisting assembly in addition to folding". Trends in Biochemical 1.Sciences 31 (7): 395-401.

[43] Kris Pauwels and other (2007). "Chaperoning Anfinsen:The Steric Foldases". Molecular Microbiology 64 (4): 917.

[44] Valapala, M., and Vishwanatha, J.K. (2011). Lipid raft endocytosis and exosomal transport facilitate extracellular trafficking of annexin A2. J. Biol. Chem. 286, 30911-30925.

[45] Raiborg, C., and H. Stenmark. 2009. The ESCRT machinery in endosomal sorting of ubiquitylated membrane proteins. Nature. 458:445-452.

[46] Hurley, J.H. (2010). The ESCRT complexes. Crit. Rev. Biochem. Mol. Biol. 45:463-487.

[47] Peinado H, Lavotshkin S, and Lyden D (2011) The secreted factors responsible for pre-metastatic niche formation: old sayings and new thoughts. Semin Cancer Biol 21:139-146.

[48] Ostrowski, M., N.B. Carmo, S. Krumeich, I. Fanget, G. Raposo, A. Savina, C.F. Moita, K. Schauer, A.N. Hume, R.P. Freitas, et al. (2010). Rab27a and Rab27b control different steps of the exosome secretion pathway. Nat. Cell Biol. 12:19-30.

[49] Cai, H., K. Reinisch, and S. Ferro-Novick. (2007). Coats, tethers, Rabs, and SNAREs work together to mediate the intracellular destination of a transport vesicle. Dev. Cell. 12:671-682.

[50] Xu, C; et al (2005). "Endoplasmic Reticulum Stress: Cell Life and Death Decisions". J. Clin. Invest 115 (10): 2656-2664.

[51] Kober L, Zehe C, Bode J (October 2012). "Development of a novel ER stress based selection system for the isolation of highly productive clones". Biotechnol. Bioeng. 109 (10): 2599-611.

[52] Bellingham, S.A., B.M. Coleman, and A.F. Hill. (2012). Small 
RNA deep sequencing reveals a distinct miRNA signature released in exosomes from prion-infected neuronal cells. Nucleic Acids Res. 40:10937-10949

[53] Nolte-'t Hoen, E.N., H.P. Buermans, M. Waasdorp, W. Stoorvogel, M.H. Wauben, and P.A. 't Hoen. (2012a). Deep sequencing of RNA from immune cell-derived vesicles uncovers the selective incorporation of small non-coding RNA biotypes with potential regulatory functions. Nucleic Acids Res. 40:9272-9285.

[54] Levine AJ (1997). p53, the cellular gatekeeper for growth and division. Cell; 88:323-31.

[55] Jin S, Levine AJ (2001). The p53 functional circuit. J Cell Sci; 114:4139-40.

[56] Snyder AR (2004). Review of radiation-induced bystander effects. Hum Exp Toxicol; 23:87-9.

[57] Azzam EI, Little JB (2004). The radiation-induced bystander effect: evidence and significance. Hum Exp Toxicol ; 23:61-5.

[58] Goldberg Z, Lehnert BE (2002). Radiation-induced effects in unirradiated cells: a review and implications in cancer. Int $\mathbf{J}$ Oncol; 21:337-49.

[59] Denzer K, Kleijmeer MJ, Heijnen HF, Stoorvogel W, Geuze HJ (2000). Exosome: from internal vesicle of the multivesicular body to intercellular signaling device. J Cell Sci; 113:3365-74.

[60] Passer BJ, Nancy-Portebois V, Amzallag N, et al (2003). The p53-inducible TSAP6 gene product regulates apoptosis and the cell cycle and interacts with Nix and the Myt1 kinase. Proc Natl Acad Sci U S A; 100:2284-9.

[61] Xu, C; et al (2005). "Endoplasmic Reticulum Stress: Cell Life and Death Decisions". J. Clin. Invest 115 (10): 2656-2664.

[62] Gercel-Taylor, C., Tullis, R. H., Atay, S., Kesimer, M., and Taylor, DD (2012).Nano particle analysis of circulating cell-derived vesicles in ovarian cancer patients. Anal. Biochem. $428,44-53$.

[63] Buschow, S.I., E.N. Nolte-'t Hoen, G. van Niel, M.S. Pols, T. ten Broeke, M. Lauwen, F. Ossendorp, C.J. Melief, G. Raposo, R. Wubbolts, et al. (2009). MHC II in dendritic cells is targeted to lysosomes or $\mathrm{T}$ cell-induced exosomes via distinct multivesicular body pathways. Traffic. 10:1528-1542.

[64] Rana, S., S. Yue, D. Stadel, and M. Zöller (2012). Toward tailored exosomes: the exosomal tetraspanin web contributes to target cell selection. Int. J. Biochem. Cell Biol. 44:1574-1584

[65] Laura Ann Mulcahy, Ryan Charles Pink and David Raul Francisco Carter (2014). Routes and mechanisms of extracellular vesicle uptake. Journal of Extracellular Vesicles 2014, 3: 24641.

[66] Hong BS, Cho JH, Kim H, Choi EJ, Rho S, Kim J, Kim JH, Choi DS, Kim YK, Hwang D, et al. (2009) Colorectal cancer cell-derived microvesicles are enriched in cell cycle-related mRNAs that promote proliferation of endothelial cells. BMC Genomics 10:556.

[67] Xiang X, Poliakov A, Liu C, Liu Y, Deng ZB, Wang J, Cheng Z, Shah SV, Wang GJ, Zhang L, et al. (2009) Induction of myeloid-derived suppressor cells by tumor exosomes. Int $J$ Cancer 124:2621-2633.

[68] Corrado, C., Raimondo,S., Chiesi, A., Ciccia,F., DeLeo,G., and Alessandro, R.(2013). Exosomes as intercellular signaling organelles involved in health and disease: basic science and clinical applications. Int. J. Mol.Sci. 14, 5338-5366.

[69] Ji, H.,Greening,D.W., Barnes, T.W., Lim, J.W.,Tauro, B.J.,Rai, A., et al.(2013). Proteome profiling of exosomes derived from human primary and metastatic colorectal cells reveal differential expression of key metastatic factors and signal transduction components. Proteomics 13, 1672-1686.

[70] Quah, B.J.,andO'Neill,H.C. (2005). Maturation of function in dendritic cells for tolerance and immunity. J. Cell. Mol. Med. 9, 643-654.

[71] Lewis,C.E., and Pollard, J.W.(2006). Distinct role of macrophages in different tumor micro environments. Cancer Res. 66, 605-612.

[72] Whiteside, T.L (2013). Immune modulation of T-cell and NK (natural killer) cell activities by TEXs (tumour derived exosomes). Biochem. Soc. Trans. 41, 245-251.

[73] Ivannikov, M. et al. (2013). "Synaptic vesicle exocytosis in hippocampal synaptosomes correlates directly with total mitochondrial volume". J. Mol. Neurosci. 49 (1): 223-230.

[74] The'ry C, Ostrowski M, and Segura E (2009) Membrane vesicles as conveyors of immune responses. Nat Rev Immunol 9:581-593.

[75] Connor DE, Exner T, Ma DD, and Joseph JE (2010) The majority of circulating platelet-derived microparticles fail to bind annexin $\mathrm{V}$, lack phospholipid dependent procoagulant activity and demonstrate greater expression of glycoproteinIb. Thromb Haemost 103:1044-1052.

[76] Giovanni Camussi and Peter J. Quesenberry (2013). Perspectives on the Potential Therapeutic Uses of Vesicles. Exosomes microvesicles, Vol. 1, 6 .

[77] Pan, B.T., Blostein, R., and Johnstone, R. M.(1983). Loss of the transferrin receptor during the maturation of sheep reticulocytes in vitro: an immunological approach. Biochem. J. 210, 37-47.

[78] Johnstone, R.M., Adam, M., Hammond, J.R., Orr, L., and Turbide, C.(1987).Vesicle formation during reticulocyte maturation. Association of plasma membrane activities with released vesicles (exosomes). J. Biol. Chem. 262, 9412-9420.

[79] Corrado,C., Raimondo, S., Chiesi, A., Ciccia, F., DeLeo, G., and Alessandro,R. (2013). Exosomes as intercellular signaling organelles involved in health and disease: basic science and clinical applications. Int. J. Mol. Sci. 14, 5338-5366.

[80] Parolini I, Federici C, Raggi C, Lugini L, Palleschi S, De Milito $\mathrm{A}$, et al (2009). Microenvironmental $\mathrm{pH}$ is a key factor for exosome traffic in tumor cells. J Biol Chem; 284: 34211-34222,

[81] Hong BS, Cho JH, Kim H, Choi EJ, Rho S, Kim J, Kim JH, Choi DS, Kim YK, Hwang D, et al. (2009). Colorectal cancer cell-derived microvesicles are enriched in cell cycle-related mRNAs that promote proliferation of endothelial cells. BMC Genomics 10:556.

[82] Xiang X, Poliakov A, Liu C, Liu Y, Deng ZB, Wang J, Cheng Z, Shah SV, Wang GJ, Zhang L, et al. (2009) Induction of myeloid-derived suppressor cells by tumor exosomes. Int $J$ Cancer 124:2621-2633.

[83] Whiteside, T.L.(2013). Immune modulation of T-cell and NK (natural killer) cell activities by TEXs (tumour derived 
exosomes). Biochem. Soc. Trans. 41, 245-251.

[84] The'ry C, Regnault A, Garin J, Wolfers J, Zitvogel L, Ricciardi-Castagnoli P, Raposo G, and Amigorena S (1999) Molecular characterization of dendritic cell-derived exosomes. Selective accumulation of the heat shock protein hsc73. J Cell Biol 147:599-610.

[85] Clayton A, Harris CL, Court J, Mason MD, and Morgan BP (2003) Antigenpresenting cell exosomes are protected from complement-mediated lysis by expression of CD55 and CD59. Eur J Immunol 33:522-531.

[86] Raposo G, Nijman HW, Stoorvogel W, Liejendekker R, Harding CV, Melief CJ, and Geuze HJ (1996) B lymphocytes secrete antigen-presenting vesicles. J Exp Med 183:1161-1172.

[87] Atay, S.,Gercel-Taylor,C., Kesimer, M., and Taylor, D.D.(2011a). Morphologic and proteomic characterization of exosomes released by cultured extravillous trophoblast cells. Exp.CellRes. 317, 1192-1202.

[88] Martínez-Lorenzo MJ, Anel A, Gamen S, Monle n I, Lasierra P, Larrad L, Pin eiro A, Alava MA, and Naval J (1999) Activated human T cells release bioactive Fas ligand and APO2 ligand in microvesicles. J Immunol 163:1274-1281.

[89] Abrahams VM, Straszewski-Chavez SL, Guller S, and Mor G (2004) First trimester trophoblast cells secrete Fas ligand which induces immune cell apoptosis. Mol Hum Reprod 10:55-63.

[90] Fra“ngsmyr L, Baranov V, Nagaeva O, Stendahl U, Kjellberg L, and Mincheva- Nilsson L (2005) Cytoplasmic microvesicular form of Fas ligand in human early placenta: switching the tissue immune privilege hypothesis from cellular to vesicular level. Mol Hum Reprod 11:35-41.

[91] Abrahams VM, Straszewski SL, Kamsteeg M, Hanczaruk B, Schwartz PE, Rutherford TJ, and Mor G (2003) Epithelial ovarian cancer cells secrete functional Fas ligand. Cancer Res 63:5573-5581.

[92] Clayton A, Mitchell JP, Court J, Linnane S, Mason MD, and Tabi Z (2008) Human tumor-derived exosomes down-modulate NKG2D expression. J Immunol 180: 7249-7258.

[93] Almqvist N, Lo“nnqvist A, Hultkrantz S, Rask C, and Telemo E (2008) Serum-derived exosomes from antigen-fed mice prevent allergic sensitization in a model of allergic asthma. Immunology 125:21-27.

[94] Korpos, E., Kadri, N., Kappelhoff, R., et al. (2013) The Peri-Islet Basement Membrane, a Barrier to Infiltrating Leukocytes in Type 1 Diabetes in Mouse and Human. Diabetes, 62, 531-542.

[95] Flanagan J, Middeldorp J, and Sculley T (2003) Localization of the Epstein-Barr virus protein LMP 1 to exosomes. J Gen Virol 84:1871-1879.

[96] van Niel G, Raposo G, Candalh C, Boussac M, Hershberg R, Cerf-Bensussan N, and Heyman M (2001) Intestinal epithelial cells secrete exosome-like vesicles. Gastroenterology $121: 337-349$.

[97] Van Niel G, Mallegol J, Bevilacqua C, Candalh C, Brugie 're S, Tomaskovic-Crook E, Heath JK, Cerf-Bensussan N, and Heyman M (2003) Intestinal epithelial exosomes carry MHC class II/peptides able to inform the immune system in mice. Gut 52:1690-1697.
[98] Segura E, Guérin C, Hogg N, Amigorena S, and The'ry C (2007) CD8_ dendritic cells use LFA-1 to capture MHC-peptide complexes from exosomes in vivo. J Immunol 179:1489-1496.

[99] Muntasell, A.; Berger, A.C.; Roche, P.A (2007). T cell-induced secretion of mhc class II-peptide complexes on b cell exosomes EMBO J., 26, 4263-4272.

[100] Zitvogel, L.; Regnault, A.; Lozier, A.; Wolfers, J.; Flament, C.; Tenza, D.; Ricciardi-Castagnoli, P.; Raposo, G.; Amigorena, S (1998). Eradication of established murine tumors using a novel cell-free vaccine: Dendritic cell-derived exosomes. Nat. Med., $4,594-600$

[101] Rautou PE, Leroyer AS, Ramkhelawon B, Devue C, Duflaut D, Vion AC, Nalbone G, Castier Y, Leseche G, Lehoux S, et al. (2011) Microparticles from human atherosclerotic plaques promote endothelial ICAM-1-dependent monocyte adhesion and transendothelial migration. Circ Res 108:335-343.

[102] Yong Zhao, Zhaoshun Jiang and Chengshan Guo (2011). New hope for type 2 diabetics: Targeting insulin resistance through the immune modulation of stem cells. Autoimmunity Reviews $11,137-142$.

[103]Feng D, Zhao WL, Ye YY, Bai XC, Liu RQ, Chang LF, et al(2010). Cellular internalization of exosomes occurs through phagocytosis. Traffic; 11: 675-687.

[104] Boilard E, Nigrovic PA, Larabee K, Watts GF, Coblyn JS, Weinblatt ME, Massarotti EM, Remold-O'Donnell E, Farndale RW, Ware J, et al. (2010) Platelets amplify inflammation in arthritis via collagen-dependent microparticle production. Science 327:580-583

[105] Bruggmann P, et al.; Swiss Hepatitis C Cohort Study (2008) Active intravenous drug use during chronic hepatitis $\mathrm{C}$ therapy does not reduce sustained virological response rates in adherent patients. J Viral Hepat 15(10):747-752.

[106] Fafi-Kremer S, et al. (2010) Viral entry and escape from antibody-mediated neutralization influence hepatitis $\mathrm{C}$ virus reinfection in liver transplantation. J Exp Med 207(9):20192031.

[107] Rashad S. Barsoum (2007) Hepatitis C virus: from entry to renal injury-facts and potentials Nephrol. Dial. Transplant. 2 2 (7): $1840-1848$

[108] Lenassi M, et al. (2010) HIV Nef is secreted in exosomes and triggers apoptosis in bystander CD4 $+\mathrm{T}$ cells. Traffic 11(1):110-122.

[109] Park IW and He JJ (2010) HIV-1 is budded from CD4 T lymphocytes independently of exosomes. Virol J 7:234

[110] Feng Z, et al. (2013) A pathogenic picornavirus acquires an envelope by hijacking cellular membranes. Nature 496(7445):367-371.

[111] Pegtel DM, Cosmopoulos K, Thorley-Lawson DA, van Eijndhoven MA, Hopmans ES, Lindenberg JL, de Gruijl TD, Wu“" rdinger T, and Middeldorp JM (2010) Functional delivery of viral miRNAs via exosomes. Proc Natl Acad Sci USA 107:6328-6333.

[112] Meckes DG Jr, Shair KH, Marquitz AR, Kung CP, Edwards RH, and Raab-Traub N (2010) Human tumor virus utilizes exosomes for intercellular communication. Proc Natl Acad Sci USA 107:20370-20375 
[113] Meckes DG Jr, Shair KH, Marquitz AR, Kung CP, Edwards RH, and Raab-Traub N (2010) Human tumor virus utilizes exosomes for intercellular communication. Proc Natl Acad Sci USA 107:20370-20375.

[114] Meckes DG Jr and Raab-Traub N (2011) Microvesicles and viral infection. $J$ Virol 85:12844-12854

[115] Chiara Corrado, Stefania Raimondo, Antonio Chiesi, Francesco Ciccia, Giacomo De Leo, and Riccardo Alessandro (2013) Exosomes as Intercellular Signaling Organelles Involved in Health and Disease: Basic Science and Clinical Applications. Int. J. Mol. Sci. 14, 5338-5366

[116] Nelson, PN; Hooley, P and Molecular Immunology Research Group (October 2004).'Human endogenous retroviruses: Transposable elements with potential?'.Clinical and Experimental Immunology 138 (138(1)): 1-9.

[117] Dino Demirovic, Suresh I.S. Rattan (2013). Establishing cellular stress response profiles as biomarkers of homeodynamics, health and hormesis. Experimental Gerontology, 48; 94-98.

[118] Park JE, Tan HS, Datta A, Lai RC, Zhang H, Meng W, Lim SK, and Sze SK (2010) Hypoxic tumor cell modulates its microenvironment to enhance angiogenic and metastatic potential by secretion of proteins and exosomes. Mol Cell Proteomics 9:1085-1099.

[119] Tourneur L, Mistou S, Schmitt A, and Chiocchia G (2008) Adenosine receptors control a new pathway of Fas-associated death domain protein expression regulation by secretion. $J$ Biol Chem 283:17929-17938.

[120] Ciravolo V, Huber V, Ghedini GC, Venturelli E, Bianchi F, Campiglio M, Morelli D, Villa A, Della Mina P, Menard S, et al. (2012) Potential role of HER2- overexpressing exosomes in countering trastuzumab-based therapy. $J$ Cell Physiol 227:658-667.

[121] Gong J, Jaiswal R, Mathys JM, Combes V, Grau GE, and Bebawy M (2012) Microparticles and their emerging role in cancer multidrug resistance. Cancer Treat Rev 38:226-234.

[122] Hakulinen J, Sankkila L, Sugiyama N, Lehti K, and Keski-Oja $\mathrm{J}$ (2008) Secretion of active membrane type 1 matrix metalloproteinase (MMP-14) into extracellular space in microvesicular exosomes. J Cell Biochem 105:1211-1218.

[123] Uno K, Homma S, Satoh T, Nakanishi K, Abe D, Matsumoto K, Oki A, Tsunoda H, Yamaguchi I, Nagasawa T, et al. (2007) Tissue factor expression as a possible determinant of thromboembolism in ovarian cancer. Br J Cancer 96:290-295.

[124] Uno K, Homma S, Satoh T, Nakanishi K, Abe D, Matsumoto K, Oki A, Tsunoda H, Yamaguchi I, Nagasawa T, et al. (2007) Tissue factor expression as a possible determinant of thromboembolism in ovarian cancer. Br J Cancer 96:290-295.

[125] Chargaff E and West R (1946) The biological significance of the thromboplastic protein of blood. J Biol Chem 166:189-197.

[126] Wolf P (1967) The nature and significance of platelet products in human plasma. Br J Haematol 13:269-288.

[127] Selkoe, D.J. (2001). Alzheimer's disease results from the cerebral accumulation and cytotoxicity of amyloid beta-protein. J. Alzheimers Dis. 3, 75-80.

[128] Rajendran, L.; Honsho, M.; Zahn, T.R.; Keller, P.; Geiger, K.D.;
Verkade, P.; Simons, K (2006). Alzheimer's disease b-amyloid peptides are released in association with exosomes. Proc. Natl. Acad. Sci. USA, 103, 11172-11177.

[129] Alvarez-Erviti, L.S.Y.; Schapira, A.H.; Gardiner, C.; Sargent, I.L.; Wood, M.J.; Cooper, J.M (2011). Lysosomal dys-function increases exosome-mediated alpha-synuclein release and transmission. Neurobiol. Dis. 42, 360-367.

[130] Surgucheva, I.; Sharov, V.; Surguchov, A. Г-synuclein (2012): Seeding of $\alpha$-synuclein aggregation andtransmission between cells. Biochemistry, 51, 4743-4754.

[131] Saman, S.; Kim, W.; Raya, M.; Visnick, Y.; Miro, S.; Saman, S.; Jackson, B.; McKee, A.; Alvarez, V.; Lee, N.; et al (2012). Exosome-associated tau is secreted in tauopathy models and is selectively phosphorylated in cerebrospinal fluid in early alzheimer disease. J. Biol. Chem. 287, 3842-3849.

[132] Kuwabara, Y.; Ono, K.; Horie, T.; Nishi, H.; Nagao, K.; Kinoshita, M.; Watanabe, S.; Baba, O.; Kojima, Y.; Shizuta, S.; et al (2011). Increased microrna-1 and microrna-133a levels in serum of patientswith cardiovascular disease indicate myocardial damage. Circ. Cardiovasc. Genet. 4, 446-454.

[133] Azevedo, L.; Janiszewski, M.; Pontieri, V.; Pedro, A.; Bassi, E.; Tucci, P.; Laurindo, F (2007). Platelet-derived exosomes from septic shock patients induce myocardial dysfunction. Crit. Care, 11, R120.

[134] Hergenreider, E.; Heydt, S.; Treguer, K.; Boettger, T.; Horrevoets, A.J.; Zeiher, A.M.; Scheffer, M.P.; Frangakis, A.S.; Yin, X.; Mayr, M.; et al. Atheroprotective communication between endothelial cells and smooth muscle cells through mirnas. Nat. Cell Biol. 2012, 14, 249-256.

[135] Zhang, H.; Liu, C.; Su, K.; Yu, S.; Zhang, L.; Zhang, S.; Wang, J.; Cao, X.; Grizzle, W.; Kimberly, R (2006). A membrane form of TNF- $\alpha$ presented by exosomes delays $\mathrm{T}$ cell activation-induced cell death. J. Immunol. 176, 7385-7393.

[136] Martinez-Lostao， L.; García-Alvarez， F.; Basáñez， G.; Alegre-Aguarón, E.; Desportes, P.; Larrad, L.; Naval, J.; Martínez-Lorenzo, M.J.; Anel, A (2010). Liposome-bound apo21/trail is an effective treatment in a rabbit model of rheumatoid arthritis. Arthritis Rheum. 62, 2272-2282.

[137] Edwin van der Pol, Anita N. Bo“ing, Paul Harrison, Augueste Sturk, and Rienk (2012) Classification, Functions, and Clinical Relevance of Extracellular Vesicles. Nieuwland, Pharmacol Rev 64:676-705.

[138] Liang, B., Peng, P., Chen, S., Li, L., Zhang, M.,Cao, D., et al. (2013). Characterization and proteomic analysis of ovarian cancer-derived exosomes. J. Proteomics 80C,171-182.

[139] Takeshita,N.,Hoshino,I., Mori,M., Akutsu,Y., Hanari, N.,Yoneyama, Y., et al. (2013).Serum microRNA expression profile: miR-1246 as a novel diagnostic and prognostic biomarker for oesophageal squamous cell carcinoma. Br.J.Cancer 108, 644-652.

[140] Mitchell, P.S., Parkin, R.K., Kroh, E.M., Fritz, B.R., Wyman, S.K., Pogosova-Agadjanyan, E.L.,et al. (2008). Circulating microRNAs as stable blood-based markers for cancer detection. Proc.Natl.Acad. Sci.U.S.A. 105, 10513-10518.

[141] Saman S, Kim W, Raya M, Visnick Y, Miro S, Saman S, Jackson B, McKee AC, Alvarez VE, Lee NC, et al. (2012) Exosome-associated tau is secreted in tauopathy models and is selectively phosphorylated in cerebrospinal fluid in early 
Alzheimer disease. J Biol Chem 287:3842-3849

[142] Mathivanan, S.; Simpson, R.J. (2009) Exocarta: A compendium of exosomal proteins and RNA. Proteomics, 9, $4997-5000$

[143] Kalra, H.; Simpson, R.; Ji, H.; Aikawa, E.; Altevogt, P.; Askenase, P.; Bond, V.C.; Borràs, F.E.; Breakefield, X.; Budnik, V.; et al (2012). Vesiclepedia: A compendium for extracellular vesicles with continuous community annotation. PLoS Biol. 10, e1001450.

[144] El-Andaloussi, S.; Lee, Y.; Lakhal-Littleton, S.; Li, J.; Seow, Y.; Gardiner, C.; Alvarez-Erviti, L.; Sargent, I.L.; Wood, M.J. (2012). Exosome-mediated delivery of sirna in vitro and in vivo. Nat. Protoc. 7, 2112-2126.

[145] Ohno, S.; Takanashi, M.; Sudo, K.; Ueda, S.; Ishikawa, A.; Matsuyama, N.; Fujita, K.; Mizutani, T.; Ohgi, T.; Ochiya, T.; et al (2013). Systemically injected exosomes targeted to egfr deliver antitumor microrna to breast cancer cells. Mol. Ther. 21, 185-191.
[146] Ratajczak J, Miekus K, Kucia M et al. (2006). Embryonic stem cell-derived microvesicles reprogram hematopoietic progenitors: evidence for horizontal transfer of mRNA and protein delivery. Leukemia; 20: 847-856.

[147] Camussi G, Deregibus MC, Bruno S et al. (2010) Exosomes/microvesicles as a mechanism of cell-to-cell communication. Kidney Int; 78: 838-848

[148] Luigi Biancone, Stefania Bruno, Maria Chiara Deregibus, Ciro Tetta and Giovanni Camussi (2012). Therapeutic potential of mesenchymal stem cell-derived microvesicles. Nephrol Dial Transplant (2012) 27: 3037-3042.

[149] Schwanhäusser B, Busse D, Dittmar G, Schuchhardt J, Wolf J, Chen W, Selbach M. (2013). "Corrigendum: Global quantification of mammalian gene expression control". Nature, 495 (7439): 126-7.

[150] Wang K, Zhang S, Weber J, Baxter D, Galas DJ. (2010). Export of microRNAs and microRNA-protective protein by mammalian cells. Nucleic Acids Res. 38: 7248-59. 